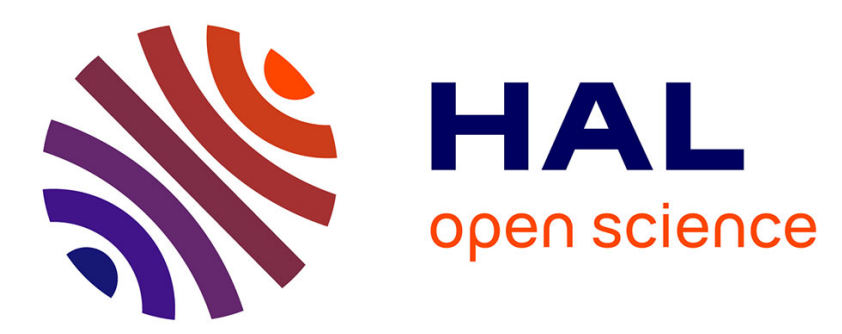

\title{
Changes in the distribution of cold waves in France in the middle and end of the 21st century with IPSL-CM5 and CNRM-CM5 models
}

Sylvie Parey, Thi Thu Huong Hoang

\section{- To cite this version:}

Sylvie Parey, Thi Thu Huong Hoang. Changes in the distribution of cold waves in France in the middle and end of the 21st century with IPSL-CM5 and CNRM-CM5 models. Climate Dynamics, 2015, 47 (3-4), pp.879-893. 10.1007/s00382-015-2877-6 . hal-01569003

\section{HAL Id: hal-01569003 \\ https://hal.science/hal-01569003}

Submitted on 26 Jul 2017

HAL is a multi-disciplinary open access archive for the deposit and dissemination of scientific research documents, whether they are published or not. The documents may come from teaching and research institutions in France or abroad, or from public or private research centers.
L'archive ouverte pluridisciplinaire HAL, est destinée au dépôt et à la diffusion de documents scientifiques de niveau recherche, publiés ou non, émanant des établissements d'enseignement et de recherche français ou étrangers, des laboratoires publics ou privés. 


\title{
1 Changes in the distribution of cold waves in France \\ 2 in the middle and end of the 21st century with IPSL- \\ 3 CM5 and CNRM-CM5 models
}

\author{
S. Parey, T.T.H. Hoang \\ EDF/R\&D 6, quai Watier 78401 Chatou Cedex France \\ Tel : 33130877614 \\ Fax : 33130877108 \\ sylvie.parey@edf.fr
}

\begin{abstract}
In this paper, a stochastic model is used to simulate daily minimum temperature time series coming from observations and two CMIP5 climate models (IPSL-CM5A-MR and CNRM-CM5) in order to analyze the changes in cold wave number and proportions under future climate conditions. The stochastic model allows computing 100 temperature time series for each different source (observation or climate model), and for 22 locations in France, which enables inferring the statistical significance of the changes. Two future time periods, near (around 2010 to 2060) and far future (around 2050 to 2100), and two RCPs (RCP4.5 and RCP8.5) are considered, while 3 different thresholds are used to identify cold waves: $0^{\circ} \mathrm{C}$ and the $10^{\text {th }}$ and $5^{\text {th }}$ percentiles of observed wintertime (December-January-February) daily minimum temperature distribution. The results show that both models project a significantly lower number of cold waves in the future, all durations considered, but the changes mainly concern the proportion of the longest cold waves (10 days and more). The decreases are higher with IPSL-CM5A-MR than with CNRM-CM5. The main driver of this change is the decreasing frequency of the observation based thresholds in the future, which is higher for IPSLCM5-MR model because the impact of a higher mean is enhanced by a decrease in the variance.
\end{abstract}

Keywords: Climate change; cold waves; stochastic modelling

\section{Introduction}

In the climate change context, more and more studies are devoted to the evolution of extreme events, since those have a major impact on people, society and organizations. Among these events, temperature related ones, heat and cold waves, are of special concern for electricity companies, because they impact both electricity production and demand. Agriculture, road or rail management or health are other examples of impacted sectors. In 2012, IPCC devoted a special report to the assessment of this issue of climate change and extreme events: the Special Report on Managing the Risks of Extreme Events and Disasters to Advance Climate Change Adaptation (SREX). Its main conclusions about temperature related extremes were that "it is very likely that there has been an overall decrease in the number of cold days and nights, and an overall increase in the number of warm days and nights, on the global scale" and "it is virtually certain that hot extremes will increase and cold extremes will decrease over 
the $21^{\text {st }}$ century with respect to the $1960-1990$ climate". However, the same report also noted that fewer studies had been devoted to the analysis of cold or warm spells compared to those devoted to changes in the frequency and intensity of cold or warm days and nights. As a consequence, less robust conclusions could have been given for those events, and essentially concern warm events: "There is medium confidence that the length or number of warm spells, including heat waves, has increased since the middle of the $20^{\text {th }}$ century". Nevertheless, the report stated that "it is very likely that the length, frequency and/or intensity of warm spells, including heat waves (defined with respect to present day climate) will increase over most land areas." Then, IPCC AR5 working group I report further supported those conclusions, in more strongly assessing the anthropogenic contribution to the observed changes. Furrer et al. (2010) and Wang et al. (2014) also have investigated the hot spell behavior by using extreme value theory. Cold waves are however an important issue for electricity management, especially in France where electrical heating is important.

In a recent set of papers, Sillmann et al. (2013) applied the climate extreme indices defined by the Expert Team on Climate Change Detection and Indices (ETCCDI) to a large number of CMIP5 and CMIP3 simulations (Coupled Model Intercomparison Projects phases 5 and 3). Among these indices, CSDI represents cold spell duration, and their results show that CMIP5 models agree with ERA-40 and ERA-Interim re-analyses in representing a decreasing trend in the cold spell duration over the period 1948-2005. Part 1 is dedicated to model evaluation, then, in part 2, they found significant changes in CSDI over land in the end of the $21^{\text {st }}$ century, with around 3.4 days less according to a RCP2.6 scenario, 3.9 days less for RCP4.5 and 4.2 days less for RCP8.5, the changes being coherent but weaker for CMIP3 models. At the European scale, De Vries et al. (2012) studied western European cold spells (where temperature falls below the $10^{\text {th }}$ percentile of the winter daily mean temperature distribution) in current and future climate. They showed that most of the changes in cold spell statistics can be explained by changes in mean (increase) and variance (decrease) of the winter temperature distribution. This dominating role of the evolutions of mean and especially variance in the evolutions of temperature extremes had also been found by Parey et al (2010). Concerning France, Cattiaux et al. (2013a) first studied the link between hot and cold spells and the dynamic circulation and its reproduction by different versions and resolutions of the IPSL climate model. They found that the model version used for CMIP5 tends to improve the wintertime dynamics and the statistics of cold spells. In another paper, Cattiaux et al. (2013b) focused on changes in cold extremes over Europe in a pilot study using both French climate models (IPSL and CNRM) AMIP (Atmospheric Model Intercomparison Project) experiments. 
Large decreases in the number of extremely cold days at the end in the $21^{\text {st }}$ century are reported, mainly driven by non dynamical mechanisms. Peings et al. (2012) analyzed the representation of observed cold waves and their change at the end of the $21^{\text {st }}$ century according to a RCP8.5 scenario with 13 CMIP5 models. They found that model biases mostly concern intensity rather than geographical extent and duration, and that these events will be less frequent at the end of the century, except for one model.

The present study aims at complementing these results by adopting a different point of view. We focus here on the local distributions of cold spells of different durations, from one single day to more than 15 consecutive days below a defined threshold. It is based on a set of high quality temperature time series provided by Météo-France and on the results of the French IPSL-CM5A-MR and CNRM-CM5 climate models run in the framework of CMIP5. Note that the version of IPSL model is different from that used in Peings et al (2012), who used the results of IPSL-CM5A-LR. Three different thresholds (one fixed, $0^{\circ} \mathrm{C}$, and two percentile based, the $10^{\text {th }}$ and $5^{\text {th }}$ percentiles of the observed wintertime -December-January-Februarytemperature distribution), two future periods (around 2010 to 2060 and the end of the $21^{\text {st }}$ century) and two climate change scenarios (RCP4.5 and RCP8.5) will be considered. The originality lies in the use of a stochastic model of temperature to bias correct and downscale the climate change simulations. Climate models are namely designed to faithfully simulate large scale features of the climate system and its circulations, as well as the main characteristics of the physical interactions, cycles and their possible evolutions under external forcing. However, they cannot precisely represent local weather and different downscaling techniques have been proposed in the literature to overcome this issue for impact studies (see Maraun et al. 2010 for a review). These techniques can be divided into statistical and dynamical approaches. Statistical methods are based on some identification of statistical relationships between large scale and local scale variables used to derive local information from the larger scale patterns given by the climate model. Dynamical methods consist in running a limited area climate model forced by the larger scale model at its boundaries in order to refine the simulation over a chosen small region. The approach used here is a statistical downscaling technique based on the use of a quite sophisticated stochastic model. This stochastic model allows moreover the simulation of a large number of equivalent temperature time series then used to evaluate the statistical significance of the obtained changes in proportions of cold spells of different duration. Furrer et al. (2010) also proposed a stochastic model, used by Wang et al. (2015) to study hot spell changes in China from CMIP5 
simulations, but only hot spells are modelled, not the whole temperature time series as is the

106 case here.

107 The considered time series, model simulations and the methodology will be described in section 2, and then section 3 will present the validation of the approach over the current climate period. Section 4 will be devoted to the analysis of the changes in the cold wave distribution in the near and far future according to RCP4.5 and RCP8.5 scenarios, before coming to the conclusion and discussion in section 5 .

\section{Data, models and methodology}

\subsection{Observation time series}

In the framework of the French IMFREX project devoted to the impact of climate change on extreme events, Météo France developed a database of daily time series selected for their homogeneity over the longest possible period after a procedure of trend and metadata analysis dedicated to the detection of possible changes in the measurement conditions (Gibelin et al. 2014). These so-called SQRs (Série Quotidiennes de Référence, reference daily time series in French) constitute a robust database of observations over France to study climate change. A set of 39 of such temperature time series have been provided by Météo-France for this study, conducted in the framework of the French national research agency supported SECIF project (dedicated to the development of climate services for the French industries). Among this set of time series, 22 daily minimum temperature time series have been selected as the longest and most representative of different locations in France, as shown in Figure 1, and they cover periods between 1953 and 2011. However, since the historical simulations of the climate models end in 2005, the observation time series are considered over periods between their beginning year and 2005. Table 1 summarizes the observed time series periods considered. The selection aimed at attributing a single station to a climate model grid cell, and thus when stations are too close, only the longest one is selected.

\section{$131 \quad 2.2$ Climate models}

132 The CNRM-CM5 and IPSL-CM5A-MR coupled ocean atmosphere GCMs are described 133 respectively in Voldoire et al. (2013) and Dufresne et al. (2012) and will just be briefly

134 presented here. The atmospheric component of CNRM-CM5 is the spectral ARPEGE-Climat 135 GCM with a T127 linear grid (256 x 128 grid points) with 31 vertical levels. The ISBA land 136 surface model, the NEMO ocean model and the GELATO sea ice model are coupled to the 137 atmospheric model through the AOSIS coupler. The atmospheric component of IPSL-CM5A- 
$138 \mathrm{MR}$ is the LMDZ model which has a $144 \times 143$ regular grid and 39 vertical levels, and is 139 coupled to the ORCHIDEE land surface scheme. The ocean model is the NEMO-OPA suites, 140 which models interactions of ocean, sea ice and marine ecosystem. Ocean atmosphere 141 coupling is done through the OASIS coupler. CNRM-CM5 and IPSL-CM5A-MR models

142 have different physical parameterizations and only share a closely resembling radiative 143 scheme.

144 For each model, the historical simulation, covering period 1950-2005, and two scenario runs, 145 RCP4.5 and RCP8.5, covering period 2006-2100 are considered. For current climate, model 146 simulations are considered over the exact same period as that of the corresponding 147 observation time series. For example, for an observation time series spanning the period 1954148 2005, the model historical simulation is considered for years 1954 to 2005. Two future 149 periods are then considered, one ending in 2060 and the other ending in 2100, the length 150 being chosen identical to the observation time series length for convenience. Thus, again, for 151 an observation time series covering 1954-2005, the first future period is 2009-2060 and the 152 second one 2049-2100.

\section{$153 \quad 2.3$ Stochastic temperature model}

154 As stated before, a stochastic temperature model is used to bias correct and downscale the 155 temperature time series provided by the climate models. This temperature generator is designed to realistically reproduce temperature extremes, and potentially simulate larger extremes than observed. It is a stochastic Functional Seasonal Heteroscedastic Auto

158 Regressive model used to simulate the stochastic part of the process after the deterministic 159 parts, trends and seasonalities in the mean and the variance, have been removed. It has namely 160 been found from analyses of a large number of different temperature time series that once 161 trends and seasonalities in the mean and the variance have been removed, no trends can be 162 identified in the other moments (up to moment 4), the auto-correlations and in the extremes of 163 the residuals (Hoang 2010). However, some seasonality remains in the other moments and in 164 the auto-correlations, but not really in the extremes. Thus the stochastic model simulates $\mathrm{Z}(\mathrm{t})$,

165 where

$$
Z(t)=\frac{X(t)-s_{m}(t)-m(t)}{s_{v(t)} s(t)}
$$

with $X(t)$ the observed temperature time series, $S_{m}(t)$ the seasonality of the mean, $m(t)$ the trend in mean, $S_{\mathrm{v}}(\mathrm{t})$ the seasonality of the standard deviation, and $\mathrm{s}(\mathrm{t})$ the trend in standard deviation. This corresponds to a standardization based on two deterministic parts of mean and standard deviation (seasonality and trend) rather than on their constant value estimated over 
the whole time period. The seasonalities are identified as trigonometric polynomials of the

171 form

$$
\theta_{0}+\sum_{i=1}^{p}\left(\theta_{i, 1} \cos \frac{2 i \pi t}{365}+\theta_{i, 2} \sin \frac{2 i \pi t}{365}\right)
$$

173 where the order $\mathrm{p}$ is chosen according to an Akaike criterion. The non parametric trends are

174 estimated by LOESS with an optimal smoothing parameter obtained through a modified 175 partitioned cross-validation technique (Hoang 2010; Dacunha-Castelle et al. 2015; Parey et al. 176 2014). Then, $\mathrm{Z}(\mathrm{t})$ is modeled as:

$$
Z(t)=b(t) Z(t-1)+a(t, Z(t-1)) \varepsilon_{t}
$$

178 With

$$
b(t)=\theta_{0}+\sum_{j=1}^{p_{1}}\left(\theta_{j, 1} \cos \frac{2 j \pi t}{365}+\theta_{j, 2} \sin \frac{2 j \pi t}{365}\right)
$$

$180 \mathrm{p}_{1}$ being again chosen according to an Akaike criterion, and a is the conditional standard deviation, obtained from the conditional variance $\mathrm{a}^{2}$ estimated as:

$$
a^{2}(t, Z(t-1))=\left(\hat{r}_{2}-t\right)\left(t-\hat{r}_{1}\right) \sum_{k=0}^{5} \sum_{j=1}^{p_{2}}\left(\alpha_{1, k}^{j} \cos \frac{2 j \pi t}{365}+\alpha_{2, k}^{j} \sin \frac{2 j \pi t}{365}\right) Z(t-1)^{k}
$$

under constraints for its first derivatives at the boundaries:

$$
\left(a^{2}\right)^{\prime}\left(r_{1}\right)=\frac{2 b\left(r_{1}\right)}{1-1 / \xi_{1}} \text { and }\left(a^{2}\right)^{\prime}\left(r_{2}\right)=\frac{2 b\left(r_{2}\right)}{1-1 / \xi_{2}}, a^{2}(t, Z(t-1))>0 \forall t
$$

and $\mathrm{p}_{2}$ chosen by Akaike criterion. Extreme value distributions for temperature are known as bounded, thus the simulation of the residuals $\mathrm{Z}(\mathrm{t})$ has to support this behavior and $\mathrm{Z}(\mathrm{t})$ is defined over an interval $\left[\mathrm{r}_{1}, \mathrm{r}_{2}\right] . \mathrm{r}_{1}$ and $\mathrm{r}_{2}$ correspond to the estimated bounds of the extreme value distributions for the left and right tails of $\mathrm{Z}(\mathrm{t})$. The constraints for the derivatives of the conditional variance are meant to force it to reach zero at the boundaries. The details and mathematical justifications for these choices can be found in Dacunha-Castelle et al. (2015).

192 The bounds $r_{1}$ and $r_{2}$ are estimated by application of the extreme value theory to the $Z(t)$ timeseries obtained from the observations, and $\xi_{1}$ and $\xi_{2}$ are the shape parameters estimated for the

194 lower and upper tail by fitting a Generalized Extreme Value distribution to the block maxima 195 (as the extremes of $\mathrm{Z}(\mathrm{t})$ are stationary, a block length of 73 days is used in order to select a 196 sufficient number of maxima to more reliably fit the distribution). $\varepsilon_{t}$ is the random part and is defined as a truncated normal distribution whose truncation depends on the value of $\mathrm{Z}(\mathrm{t}-1)$. 
198 Then a simulation of the initial temperature time series is obtained by re-introducing the 199 estimated deterministic parts.

200 The stochastic model is fitted to the residuals obtained from the observed time series, and 201 then, seasonalities and trends coming either from the observations or from the climate model 202 time series are used to reconstruct temperature time-series from the simulated residual time 203 series. In this study, 100 simulations of the residuals for each of the 22 observed temperature 204 time series have been considered.

\subsection{Simulated temperature time series}

206 As stated before, for each location 100 time series of the residuals $\mathrm{Z}(\mathrm{t})$, after removing trends and seasonalities, are computed. The ability of the model to reproduce the observed behavior of Z(t) has been checked in Hoang (2010), Dacunha-Castelle et al. (2015) and Parey et al. (2014), thus, from these, 100 temperature time series coherent with the observed one are obtained by reintroducing trends and seasonalities. For climate model temperature time series, potential biases have first to be investigated. Seasonality is the first estimated deterministic part, and trend is identified from the time series of anomalies from the seasonality. The same procedure is applied to observed and model temperature time series, and when comparing the obtained seasonalities and trends, it appears that most of the model bias is embedded in the seasonality identification, while trends are then more coherent with the observed ones. Figure 2 illustrates this point for the station of Cannes, in the south of France. Thus, the reconstructed temperature time series for present climate are built by adding (multiplying by for standard deviation) observed seasonalities and climate model trends to the simulated residuals $\mathrm{Z}(\mathrm{t})$. Then, for future time periods, seasonalities are obtained by adding the modeled difference in seasonality of the mean between future and present period for the seasonality in the mean, and multiplying by the ratio of future period standard deviation seasonality to present period one for the seasonality of the standard deviation:

$\mathrm{S}_{\mathrm{mf}}=\mathrm{S}_{\mathrm{mo}}+\left(\mathrm{S}_{\mathrm{mm} 2}-\mathrm{S}_{\mathrm{mm} 1}\right) ; \quad \mathrm{S}_{\mathrm{vf}}=\mathrm{S}_{\mathrm{vo}} * \mathrm{~S}_{\mathrm{vm} 2} / \mathrm{S}_{\mathrm{vm} 1}$ with $\mathrm{S}_{\mathrm{m}}$ denoting seasonality of the

mean, $S_{v}$ seasonality of the standard deviation, and subscripts $\mathrm{f}, \mathrm{o}, \mathrm{m} 1$ and $\mathrm{m} 2$ denoting respectively future period, observation, model present period and model future period. Figure 3 illustrates such a reconstruction for the same station of Cannes.

\subsection{Cold waves}

Cold waves are defined here as cold spells with one or more consecutive days with daily minimum temperature below a chosen low threshold. In this study, three thresholds are considered: a fix threshold, $0^{\circ} \mathrm{C}$, and two low percentiles: the $10^{\text {th }}$ and $5^{\text {th }}$ percentiles of the 
231 observed wintertime daily minimum temperature distribution over the observation period.

232 Winter is the climatological winter covering the months of December, January and February 233 (DJF).

\section{Validation for present period}

\subsection{Climate and stochastic models performances}

In a first step, the repartitions of all identified cold spells for each station between different durations are compared for observation and climate model present period simulations. As climate models have biases, the thresholds used to define cold waves are chosen as the corresponding percentiles of the climate model time series. Thus, the fixed $0^{\circ} \mathrm{C}$ threshold is not $0^{\circ} \mathrm{C}$ for the models, but the value corresponding in the model time series to the percentile of $0^{\circ} \mathrm{C}$ in the observations. The $5^{\text {th }}$ and $10^{\text {th }}$ percentile of wintertime temperature correspond similarly to different temperature values in the model runs and in the observations. The comparisons show that generally, both climate models tend to produce fewer 1-day events and more 2 days and more ones than observed, and may have difficulties to reproduce very long cold spells. The stochastic model generally leads to a better reproduction of the proportion of long events, but tends to overestimate that of 1-day ones. Figure 4 illustrates this behavior for the station of Tomblaine and the $10^{\text {th }}$ percentile threshold. It can be noticed that the stochastic model is able to produce long cold waves in some simulations, even though none has been observed (14 days or $>15$ days in Figure 4 right panel). With a more extreme threshold like the $5^{\text {th }}$ percentile of wintertime temperature, the climate and stochastic models both have difficulties to produce a similar proportion of very long events as observed, although the stochastic model again sometimes succeeds in producing some among the 100 simulations, even though none have been observed.

Besides, using the stochastic model allows inferring significance for the observed changes with the computation of the $95 \%$ confidence interval for the distributions obtained from the 100 simulations of each proportion of cold spell duration. Figure 5 illustrates the mean number of cold waves per year for the $0^{\circ} \mathrm{C}$ threshold, all durations gathered, for the different considered locations in France. Black circles indicate the stations for which the simulated mean number is significantly different from the observed one (the observed number does not fall inside the $95 \%$ confidence interval of simulated numbers). These discrepancies are mainly due to the previously mentioned tendency to produce much more 1-day events than observed, whereas the proportions of longer cold spells are more faithfully represented. Then, the 
repartitions of cold spells computed from the stochastic simulations for the current period reconstructed with observed seasonalities and trends or observed seasonalities and climate model trends are very similar, as can be seen in Figure 6 for Tomblaine and the longest cold spells.

\subsection{Use in the climate change context}

In order to check the ability of the suggested methodology to be used in the climate change context, a cross-validation has been conducted for one location. The temperature time series of Champhol, observed over period 1954 and 2005, has been split into two periods of equal length: 1954-1979 and 1980-2005 (26 years each). The stochastic model has been calibrated over the first period, and 100 simulations have been made. Then, the minimum temperature time series for the second period has been reconstructed using first period seasonalities corrected using climate model seasonality differences between both periods and climate model trends for the second period, following the suggested methodology for future climate. Figure 7 shows that the obtained proportions of cold spells are similar to that which would have been obtained by using observed period 2 seasonalities and trends. Figure 7 is for the $10^{\text {th }}$ percentile threshold but this holds true for all used thresholds. This result gives confidence in the use of this methodology to derive bias corrected future temperature time series.

\section{Future changes in cold waves number and repartitions}

\subsection{Cold waves number}

Then, the changes projected for the future are analyzed, considering the same observation based thresholds for the present and future periods. In line with all previous studies on the subject, the mean number of cold spells per year, all durations considered, decreases whichever the future time period, RCP scenario or threshold chosen for the identification. For the nearest future period until 2060, both scenarios not surprisingly give relatively similar results for both models, but IPSL-CM5A-MR model generally projects larger decreases than CNRM-CM5: around 1 to 5 less episodes per year for $0^{\circ} \mathrm{C}$, up to 2 less for the $5^{\text {th }}$ percentile and around 2 to 3 less for the $10^{\text {th }}$ percentile with IPSL-CM5A-MR and around 1 to 4 less episodes per year for $0^{\circ} \mathrm{C}, 1$ (more rarely 2 ) less for the $5^{\text {th }}$ percentile and 1 to 2 less for the $10^{\text {th }}$ percentile with CNRM-CM5. The decreases are larger for the far future period with generally one to 2 events less than for the nearest period. Figure 8 illustrates these results for 
the $10^{\text {th }}$ percentile threshold and each model and both near and far future periods for RCP4.5.

298 The black circles denote significant changes and show that all changes are significant.

\subsection{Cold waves repartitions}

301 We just saw that the mean number of excursions under the different thresholds, whatever their 302 lengths, is projected to decrease in the future. Now, let's go further and see how the 303 repartition among the different event durations is changed. Among this lower total number of 304 cold spells, in the nearest future period, only the proportion of the longest events (15 days and 305 more for $0^{\circ} \mathrm{C}, 10$ days and more for the $5^{\text {th }}$ percentile and 11 to 12 days or more for the $10^{\text {th }}$ percentile) significantly decreases, and once again, more according to IPSL-CM5A-MR model than according to CNRM-CM5 model. The results are again similar for both RCPs until 2060, although a little bit higher for RCP8.5. For the end of the century, the picture looks similar but the significant decreases concern all stations and begin for shorter events. Here, the impact is larger with RCP8.5 than with RCP4.5, IPSL-CM5A-MR giving again a stronger response than CNRM-CM5. Significant decreases in proportions concern events during 5 days and more for $0^{\circ} \mathrm{C}, 8$ days or more ( 4 days at some locations) for the $5^{\text {th }}$ percentile and 10 days or more (again, less for less cold places) for the $10^{\text {th }}$ percentile. Figure 9 illustrates these results for the period until 2100 , both models and scenarios and for the $5^{\text {th }}$ percentile threshold.

\subsection{Role of observation based threshold in the changes}

Previous results are obtained with the same threshold for the identification of cold waves for present and future periods. However, due to climate change, these thresholds become rarer in both future periods than nowadays. In order to identify the impact of this change on previous results, the cold spell repartitions have been estimated again from the stochastic simulations of the observations, but using as thresholds the values corresponding to the previously defined threshold location in future wintertime temperature distributions. Thus, the observation based $5^{\text {th }}$ and $10^{\text {th }}$ threshold for example correspond to $2^{\text {nd }}$ to $4^{\text {th }}$ and $5^{\text {th }}$ to $8^{\text {th }}$ percentile for the nearest period, around $1^{\text {st }}$ and $2^{\text {nd }}$ to $4^{\text {th }}$ percentile for the late period, depending on the model scenario and location. They thus lie in the farthest tail of the distribution, which could largely explain the observed changes in number and repartitions of cold waves. When using such threshold for the observations and comparing to the previously obtained results for the future periods, we can observe that they generally look very similar, confirming the upmost role 
331 for the late period (late 2040s to 2100), RCP4.5 and the current period $5^{\text {th }}$ percentile of 332 wintertime temperature distribution as threshold. Significant changes appear for similar cold 333 spell lengths, the differences rarely exceeding one or 2 days. For one station and IPSL-CM5334 MR, a difference of 4 days can be noticed (circled in red in Figure 9): the significant decrease 335 is found from 13 days with the observation based threshold and 9 days with the future one. 336 After checking, it appears that the simulations do not produce 9-day cold spells with the 337 future threshold, but produce a similar (even slightly higher) proportion of 10-day ones, and 338 then, for the longest spells, the results are coherent. As the 10-day spells do not change, the 339 coherent decrease is rather for 11 days and more and then, the results can be considered as 340 similar. The reason for this absence of 9-day spells will have to be further investigated, but 341 the proportion become very small for such lengths and a small change, induced by different 342 trends, can induce such a result. It seems then that the dynamic of cold spells does not change 343 much in the future, and the frequency of current cold waves decreases because current cold 344 temperatures become less frequent. Now let us compare the threshold shifts given by each 345 climate model. As an example, Figure 11 illustrates them for the station of Boulogne sur mer, 346 in the north of France: for IPSL-CM5-MR, due to both mean increase and variance decrease 347 (or location and scale of the distribution), the observation based $5^{\text {th }}$ percentile of wintertime 348 temperature distribution (around $-5^{\circ} \mathrm{C}$ for this station), becomes a $0.5^{\text {th }}$ percentile in the future. 349 Such a decrease in the variance is not projected by CNRM-CM5, and the $5^{\text {th }}$ percentile of 350 observation distribution becomes a $1.5^{\text {th }}$ percentile of the future wintertime distribution. Both 351 mean and variance change impact the percentile change, and the difference in variance change 352 explains why the impact is found higher with IPSL-CM5-MR than with CNRM-CM5. Cold 353 spell length decreases in the future mainly because the frequency of current thresholds 354 decreases, and this decrease is linked to both mean and variance changes. It must be recalled 355 here that when the threshold becomes rarer, the climate and the stochastic models both have 356 difficulties to produce long cold waves, which could artificially intensify the identified 357 impact.

\section{Conclusion and discussion}

360 In this study, a stochastic temperature generator has been used to bias correct and downscale 361 climate simulation results and analyze the future changes in cold waves number and 362 repartition. Cold waves are defined as consecutive days (from 1 single day to more than 15 363 days) with daily minimum temperature below different thresholds: $0^{\circ} \mathrm{C}$ or the $10^{\text {th }}$ and $5^{\text {th }}$ 
percentiles of observed wintertime daily minimum temperature distribution. For future period, two climate model simulations have been considered, one according to RCP8.5 scenario and the other according to RCP4.5, with only two climate models used in the framework of the CMIP5 exercise: CNRM-CM5 and IPSL-CM5A-MR. The main outcomes are the following:

- Using the stochastic model allows both simulating some very long events, even though none have been observed, and inferring the significance of changes by use of the confidence intervals derived from 100 simulations for each period

- In agreement with all previous studies, a significant decrease in the number of cold spells is found in the future, whichever the future period, model or scenario

- Among these fewer cold waves, the decreasing essentially concerns the longest ones, with smaller differences for the nearest future period, whichever the scenario, and with CNRM-CM5 model

- The main driver of the changes is the threshold shift: observation based thresholds are rarer in the future due to climate warming

- For IPSL-CM5-MR, the variance decrease add to the mean increase to make current thresholds even rarer in the future, which explains the highest impact found with this model

The fact that in winter, variance decreases when mean increases, has already been evidenced in Parey et al. 2010. However, the present study shows that two different models may have a different behavior in this respect, the decrease in temperature variance being much lower for CNRM-CM5 than for IPSL-CM5A-MR. This study should thus be extended to the consideration of more climate models. It could be interesting to apply the same methodology to heat waves too, in order to compare the impacts. Schoetter et al. 2015 also found that for heat waves, the main driver is the threshold shift, and considering the respective roles of shift and broadening of the distributions, found no significant change in variance, and thus, a dominating role for the mean change, whereas here the variance change seems to play a more important role for cold spells. One advantage of the methodology used here is the decomposition of the signal between 2 deterministic parts, seasonality and trend, both for mean and variance, and a stochastic signal. Academic tests will be done with prescribed changes in the different deterministic components in order to quantify their respective roles in the change of extreme temperature events. In parallel, suggestions and tests are under way to improve the stochastic model in order to fix its tendency to produce too much single day events and too few very long ones, especially when the threshold is extreme (typically lower than the $5^{\text {th }}$ percentile). 
Acknowledgment: This work is supported by the SECIF project from the French National Research Agency (ANR). Special thanks to S. Denvil (IPSL) for providing the CMIP5 simulations, to Paul-Antoine Michelangeli (EDF/R\&D) for preparing and managing the EDF climate model results database, and to G. Gayraud (MétéoFrance) for providing the SQR temperature time series.

403

\section{References}

Cattiaux J., Douville H., Ribes A., Chauvin F., Plante C. (2013): Towards a better understanding of changes in wintertime cold extremes over Europe: a pilot study with CNRM and IPSL atmospheric models. Climate Dynamics, Volume 40, Issue 9, pp 2433-2445 doi $10.1007 / \mathrm{s} 00382-012-1436-7$

Cattiaux J., Quesada B., Arakélian A., Codron F., Vautard R., Yiou P. (2013) : North-Atlantic dynamics and European Temperature Extremes in the IPSL model: sensitivity to atmospheric resolution. Climate Dynamics, Volume 40, Issue 9, pp 2293-2310 doi 10.1007/s00382-012$1529-3$

413 Dacunha-Castelle D., Hoang T.T.H., Parey S. (2015): Modeling of air temperatures: preprocessing and trends, reduced stationary process, extremes, simulation, Journal de la Société Française de Statistique, volume 156, No1, pp 138-168

416 de Vries H, Haarsma RJ, Hazeleger W (2012) Western European cold spells in current and 417 future climate. Geophys Res Lett 39:L04706. doi:10.1029/2011GL050665

418 Dufresne J-L, Foujols M-A, Denvil S., Caubel A., Marti O., Aumont O, Balkanski Y, Bekki 419 S., Bellenger H, Benshila R, Bony S, Bopp L, Braconnot P, Brockmann P, Cadule P, Cheruy 420 F, Codron F, Cozic A, Cugnet D, de Noblet N, Duvel J-P, Ethé C, Fairhead L, Fichefet T, 421 Flavoni S, Friedlingstein P, Grandpeix J-Y, Guez L, Guilyardi E, Hauglustaine D, Hourdin F, Idelkadi A, Ghattas J, Joussaume S, Kageyama M, Krinner G, Labetoulle S, Lahellec A, Lefebvre M-P, Lefevre F, Levy C, Li Z. X,. Lloyd J, Lott F, Madec G, Mancip M, Marchand 424 M, Masson S, Meurdesoif Y, Mignot J, Musat I, Parouty S, Polcher J, Rio C, Schulz M, 425 Swingedouw D, Szopa S, Talandier C, Terray P, Viovy N, Vuichard N (2013): Climate 426 change projections using the IPSL-CM5 Earth System Model: from CMIP3 to CMIP5, 427 Climate Dynamics Volume 40, Issue 9, pp 2123-2165

428 Furrer, E. M., R. W. Katz, M. D. Walter, and R. Furrer (2010): Statistical modeling of hot 429 spells and heat waves. Climate Research, 43, pp 191-205.

430 IPCC (2012): Managing the Risks of Extreme Events and Disasters to Advance Climate 431 Change Adaptation. A Special Report of Working Groups I and II of the Intergovernmental 
432 Panel on Climate Change, Cambridge University Press, Cambridge, UK, and New York, NY, 433 USA, $582 \mathrm{pp}$.

434 IPCC (2013): Climate Change 2013: The Physical Science Basis. Contribution of Working 435 Group I to the Fifth Assessment Report of the Intergovernmental Panel on Climate Change 436 [Stocker, T.F., D. Qin, G.-K. Plattner, M. Tignor, S.K. Allen, J. Boschung, A. Nauels, Y. Xia, 437 V. Bex and P.M. Midgley (eds.)]. Cambridge University Press, Cambridge, United Kingdom 438 and New York, NY, USA, 1535 pp, doi:10.1017/CBO9781107415324.

439 Gibelin AL, Dubuisson B, Corre L, Deaux N, Jourdain S, Laval L, Piquemal JM, Mestre O, 440 Dennetière D, Desmidt S, Tamburini A (2014): Evolution de la température en France depuis 441 les années 1950 : Constitution d'un nouveau jeu de séries homogénéisées de référence, La 442 Météorologie, 87, 45-53, DOI : 10.4267/2042/54336

443 Hoang, T. T. H. (2010), Modélisation de séries chronologiques non stationnaires, non 444 linéaires: application à la définition des tendances sur la moyenne, la variabilité et les 445 extrêmes de la température de l'air en Europe, $\mathrm{PhD}$ thesis work (written in English), 446 http://www.tel.archivesouvertes.fr/tel-00531549/fr/

447 Maraun D, Wetterhall F, Ireson AM, Chandler RE and others (2010): Precipitation 448 downscaling under climate change: recent developments to bridge the gap between dynamical 449 models and the end user. Rev Geophys 48: RG3003, doi: 10.1029/2009RG000314

450 Parey, S., D. Dacunha-Castelle, and T. T. H. Hoang (2010): Mean and variance evolutions of 451 the hot and cold temperatures in Europe, Climate Dynamics, Volume 34, pp 345-369.

452 Parey, S., T. T. H. Hoang, and D. Dacunha-Castelle (2013): The importance of mean and 453 variance in predicting changes in temperature extremes, J. Geophys. Res., 118, 8285-8296, 454 doi:10.1002/jgrd.50629

455 Parey S., Hoang T.T.H., Dacunha-Castelle D. (2014): Validation of a stochastic temperature 456 generator focusing on extremes and an example of use for climate change, Climate Research, 457 Vol. 59, pp 61-75

458 Peings Y., Cattiaux J., Douville H. (2013): Evaluation and response of winter cold spells over 459 western Europe in CMIP5 models. Climate Dynamics, Volume 41, pp 3025-3037, doi $460 \quad 10.1007 / \mathrm{s} 00382-012-1565-\mathrm{z}$

461 Schoetter R., Cattiaux J., Douville H. (2015): Changes of western European heat wave 462 characteristics projected by the CMIP5 ensemble. Climate Dynamics, Volume 45, Issue 5, pp $463 \quad 1601-1616$

464 Sillmann J., Kharin V.V., Zhang X., Zwiers S.W. and Bronaugh D. (2013): Climate extremes 465 indices in the CMIP5 multimodel ensemble: Part 1. Model evaluation in the present climate. 
466 Journal of Geophysical Research: Atmospheres, volume 118, pp 1716-1733, 467 doi:10.1002/jgrd.50203

468 Sillmann J., Kharin V.V., Zhang X., Zwiers S.W. and Bronaugh D. (2013): Climate extremes 469 indices in the CMIP5 multimodel ensemble: Part 2. Future climate projections. Journal of 470 Geophysical Research: Atmospheres, volume 118, pp 2473-2493, doi:10.1002/jgrd.50188

471 Voldoire A, Sanchez-Gomez E, Salas y Melia D, Decharme B, Cassou C, Senesi S, Valcke S, 472 Beau I, Alias A et al (2013) The CNRM-CM5.1 global climate model: description and basic 473 evaluation. Climate Dynamics, Volume 40, Issue 9, pp 2091-2121, doi:10.1007/s00382-011$474 \quad 1259-\mathrm{y}$

475 Wang,W., W. Zhou, Y. Li, and X. D. Wang (2014): Statistical modeling and CMIP5 476 simulations of hot spell changes in China. Climate Dynamics, volume 44, pp 2859-2872.

477

478

479

480

481

482

483

484

485

486

487

488

489

490

491

492

493

494

495

496

497

498

499 
Tables

\begin{tabular}{|c|c|c|}
\hline Number & Location & Period \\
\hline 1 & Château Gaillard & $1953-2005$ \\
\hline 2 & Cannes & $1959-2005$ \\
\hline 3 & Chateaubernard & $1953-2005$ \\
\hline 4 & Farges en Septaine & $1953-2005$ \\
\hline 5 & Saint Cast le Guildo & $1955-2005$ \\
\hline 6 & Besançon & $1959-2005$ \\
\hline 7 & Montélimar & $1959-2005$ \\
\hline 8 & Champol & $1954-2005$ \\
\hline 9 & Guipavas & $1958-2005$ \\
\hline 10 & Beaucouze & $1955-2005$ \\
\hline 11 & Auderville & $1955-2005$ \\
\hline 12 & Courcy & $1959-2005$ \\
\hline 13 & Saint Dizier & $1959-2005$ \\
\hline 14 & Tomblaine & $1959-2005$ \\
\hline 15 & Augny & $1959-2005$ \\
\hline 16 & Boulogne sur mer & $1955-2005$ \\
\hline 17 & Epinoy & $1955-2005$ \\
\hline 18 & Strasbourg & $1959-2005$ \\
\hline 19 & Mont Saint Vincent & $1953-2005$ \\
\hline 20 & Sainte Adresse & $1955-2005$ \\
\hline 21 & Vélizy Villacoublais & $1954-2005$ \\
\hline 22 & Saint Georges la Baulche & $1954-2005$ \\
\hline
\end{tabular}

501 Table 1: list of the observed time series locations with their observation period considered for 502 present climate 


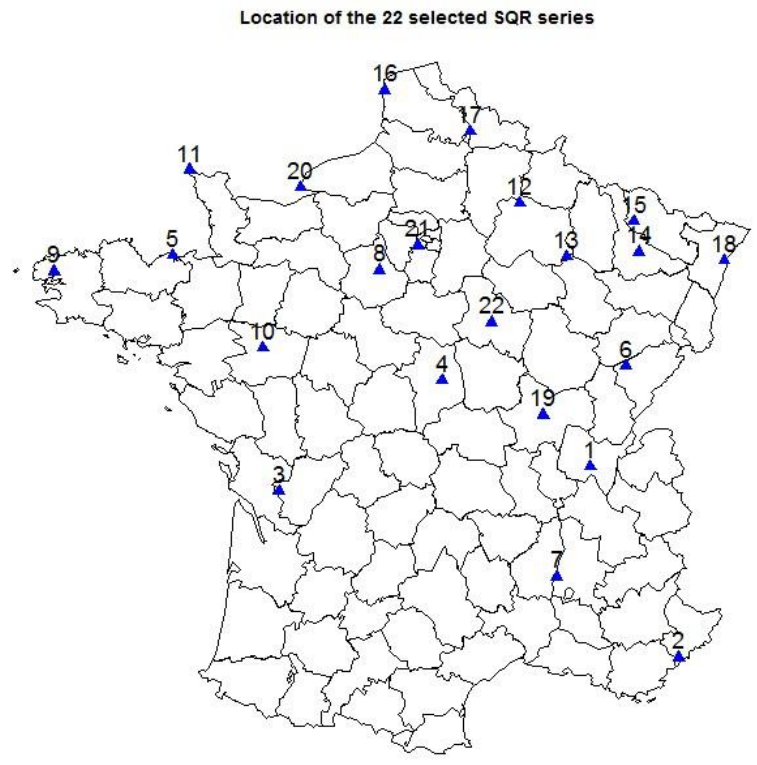

Figure 1: location of the 22 selected daily minimum temperature time series; the numbers 507 refer to table 1 for the location identification 


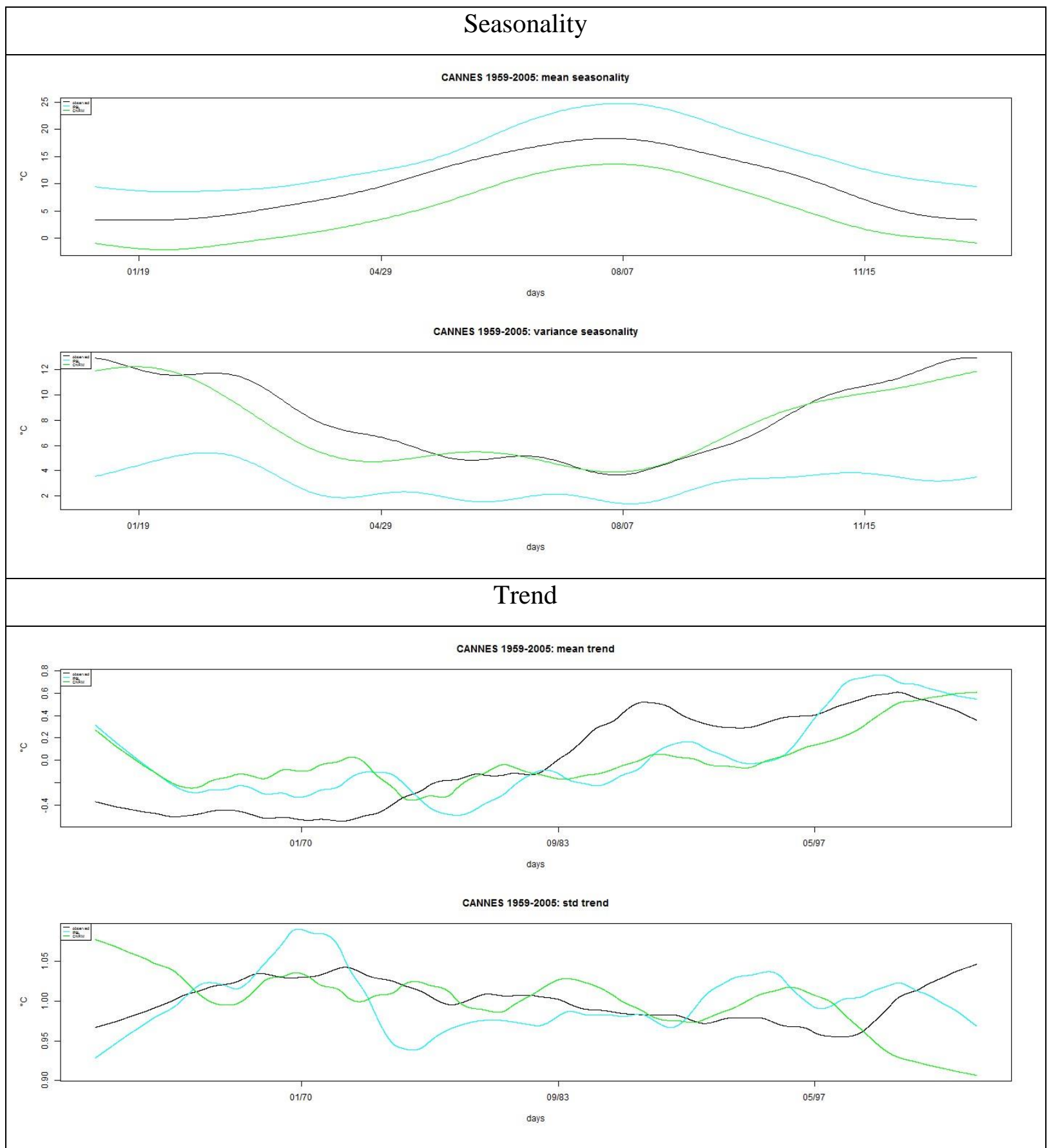

510 Figure 2: seasonality (top panel: mean top and variance bottom) and trend (bottom panel:

511 mean top and variance bottom) of the observed (black curves), IPSL-CM5A-MR (cyan) and

512 CNRM-CM5 (green) daily minimum temperature time series for Cannes, in the south of 513 France 


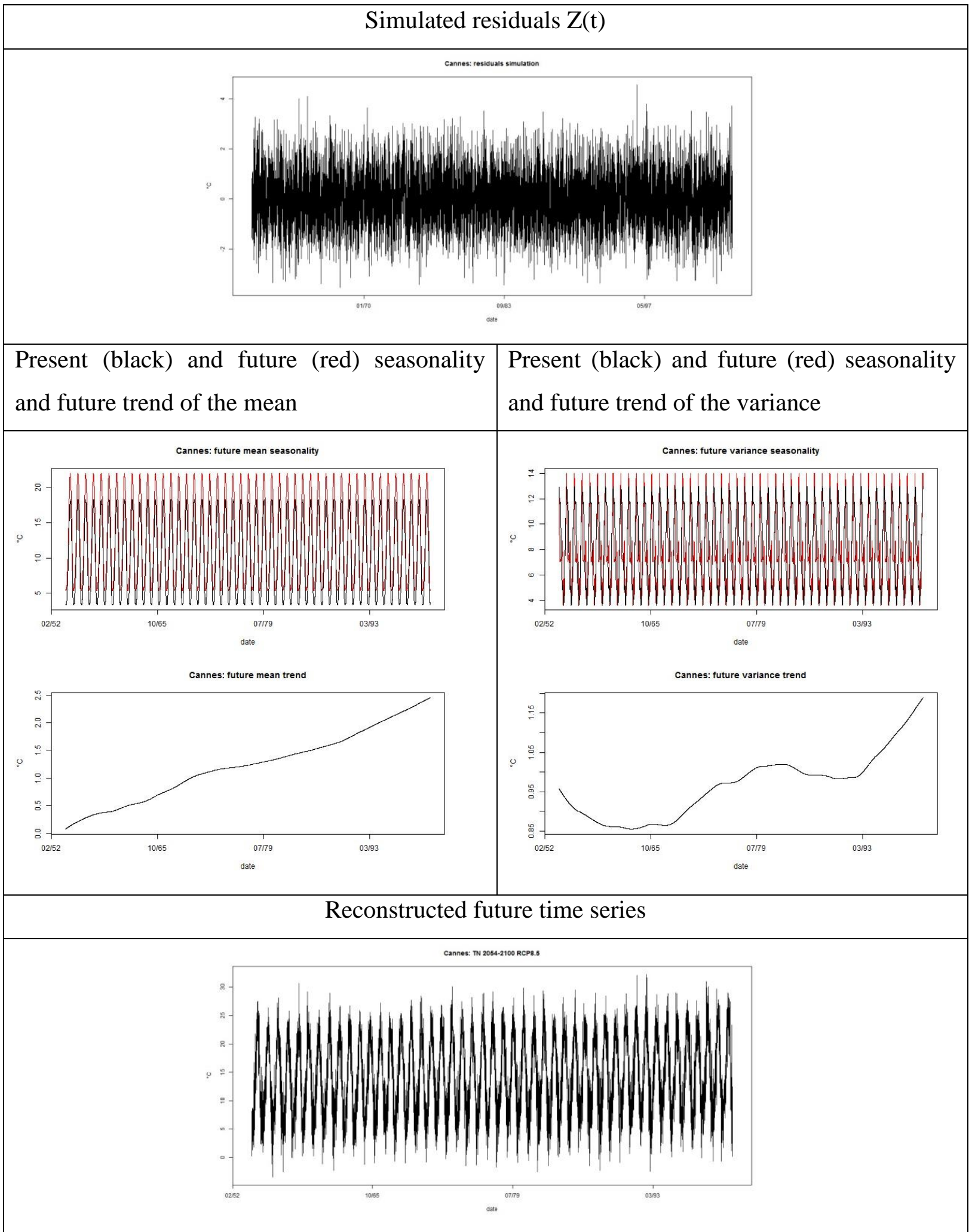

516 Figure 3: reconstruction of a future daily minimum temperature time series (bottom panel)

517 from the simulated residuals (top panel), the future seasonalities and trends (middle panel, for 518 seasonality: black $=$ present, red $=$ future) for the mean (left panel) and the variance (right 519 panel) 


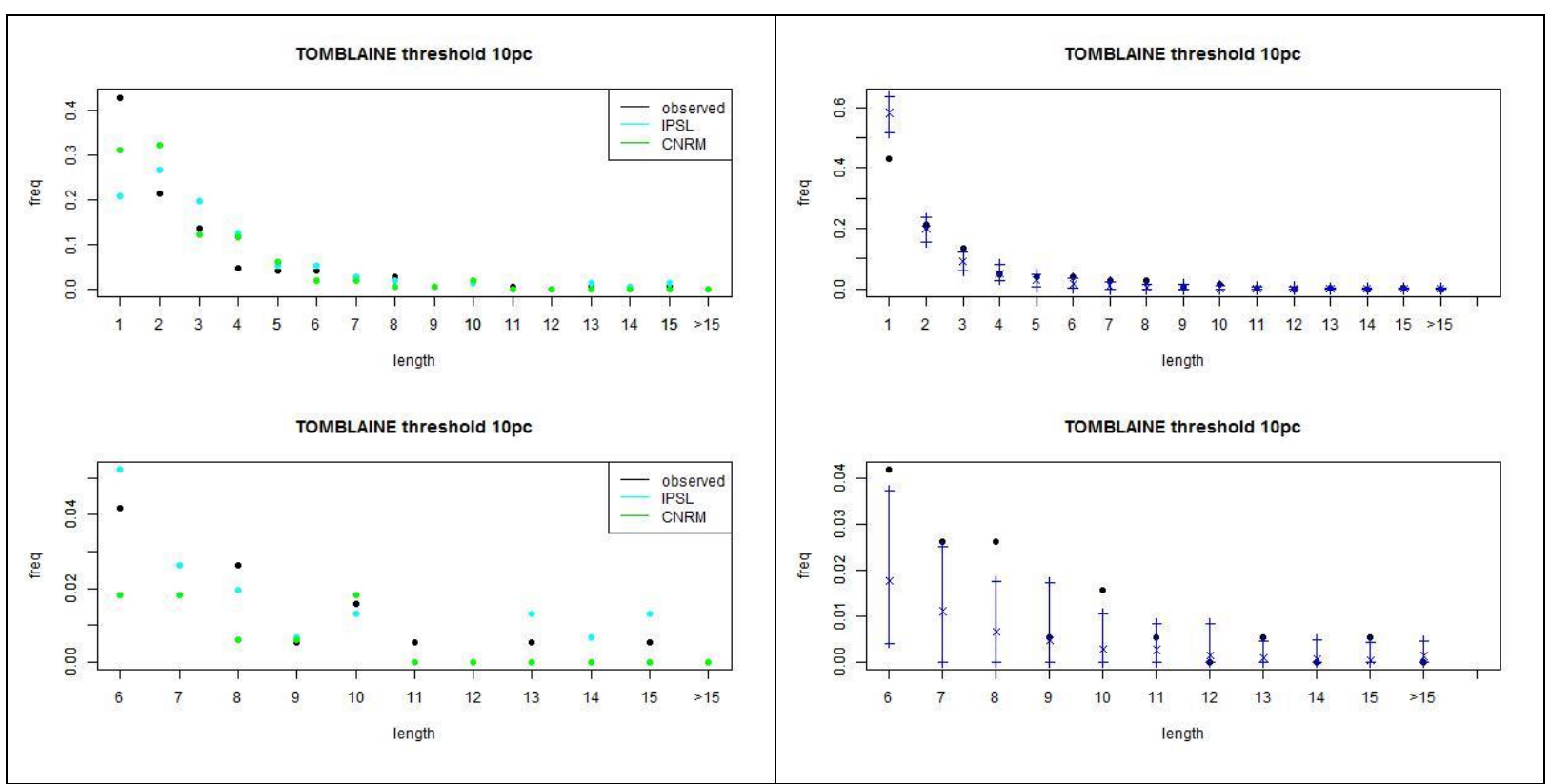

520 Figure 4: cold spells repartition with a $10^{\text {th }}$ percentile threshold from the climate models (left 521 panel: observation in black, IPSL-CM5A-MR in cyan and CNRM-CM5 in green) and with 522 the stochastic model (right panel: observation in black, distribution for the 100 simulations in 523 blue: $x$ mean and +2.5 and 97.5 percentiles) for the station of Tomblaine. Top plots represent 524 all cold wave lengths while bottom plots zoom on the longest ones (6 days and more) 


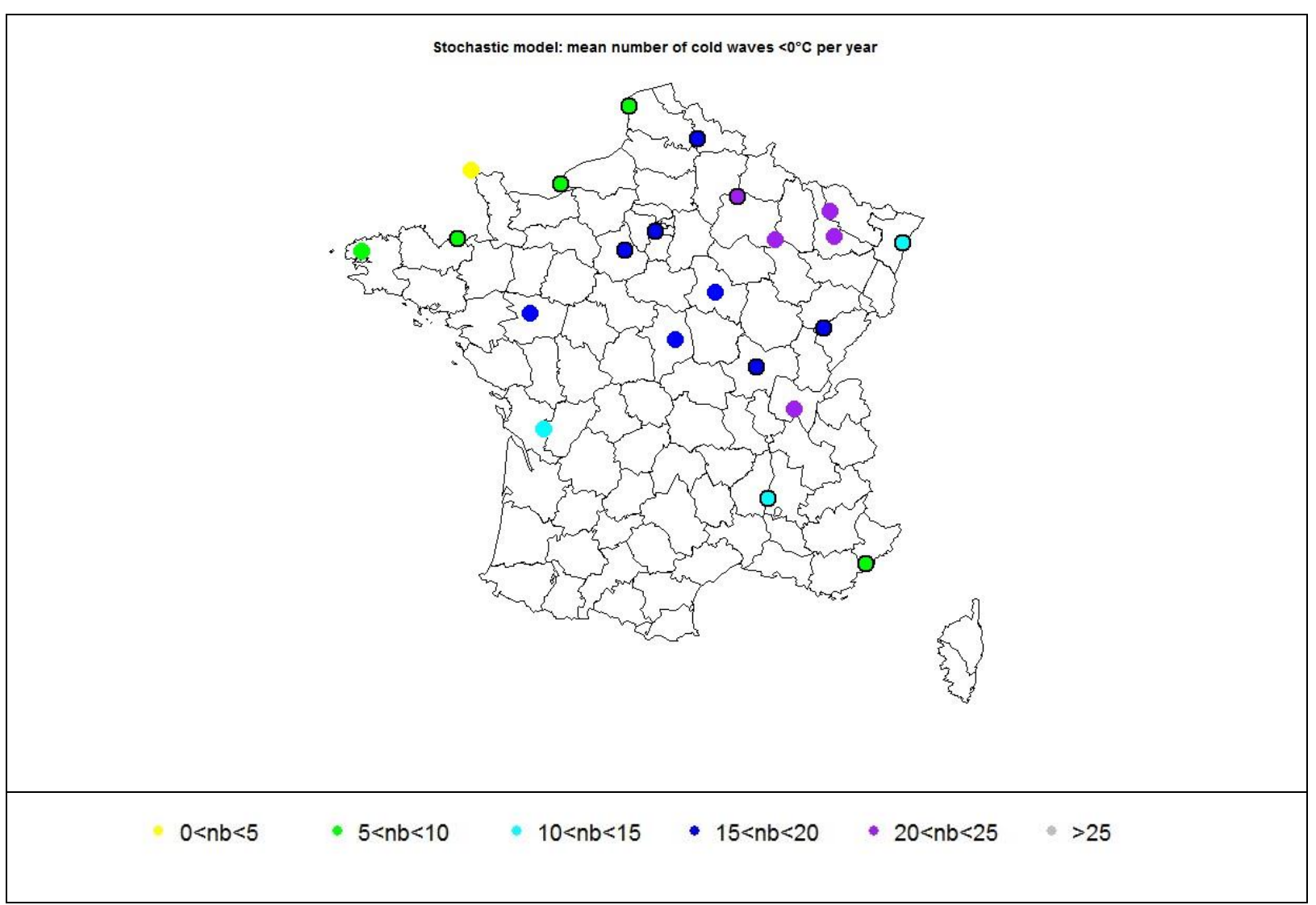

527 Figure 5: mean number of observed cold spells per year with $0^{\circ} \mathrm{C}$ threshold. Black circling 528 denotes the locations where the observed number does not fall inside the $95 \%$ confidence 529 interval of the stochastic simulations 


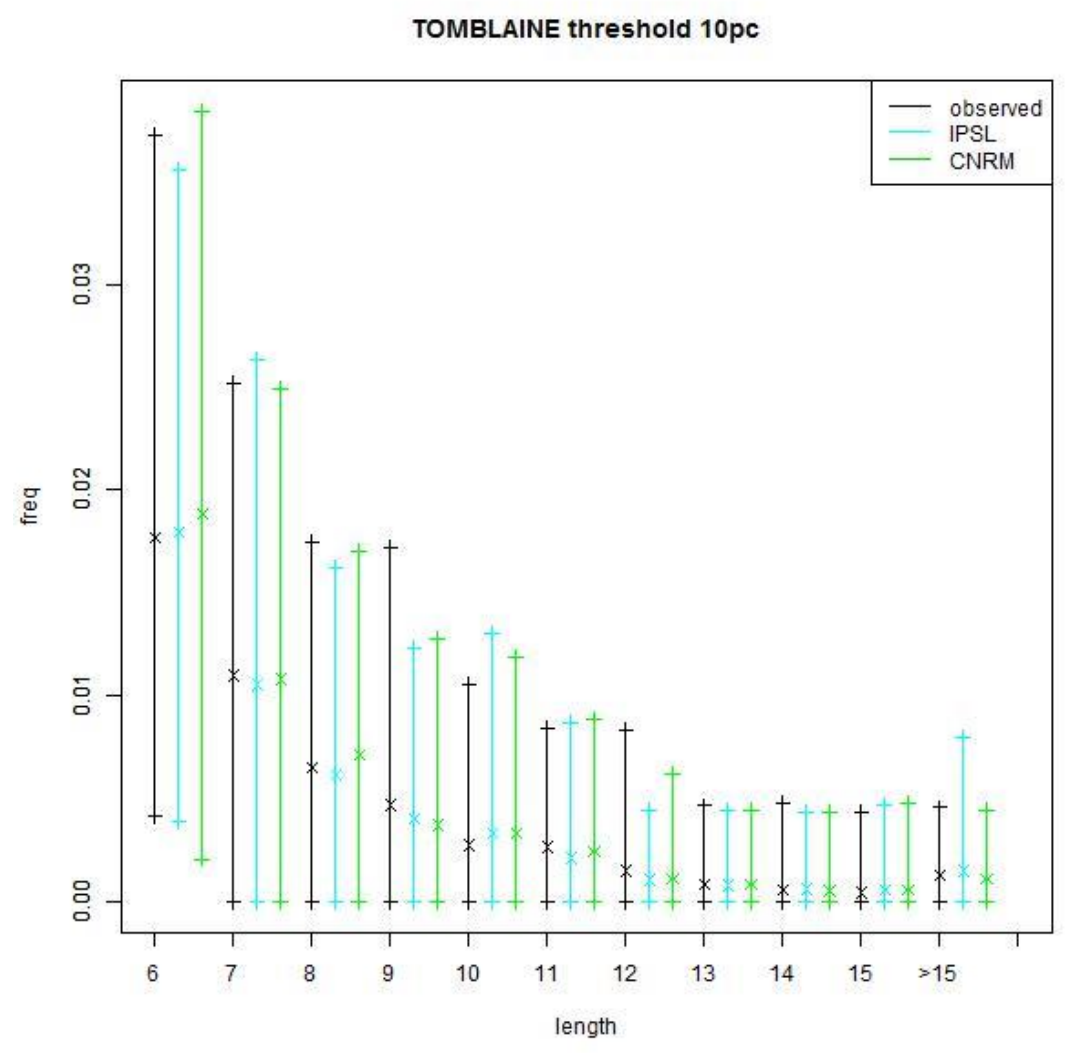

532 Figure 6: distributions of proportions of the longest cold waves (6 days and more) obtained 533 with the stochastic model for the station of Tomblaine from the observations (simulated 534 residuals + observed seasonalities and trends, black), and from IPSL-CM5A-MR (blue) and 535 CNRM-CM5 (green) (simulated residuals + observed seasonalities and model trends). Cross 536 is for the mean value, and start and end of the segments are the 2.5 and 97.5 percentiles of the 537 distribution obtained from the 100 simulations 


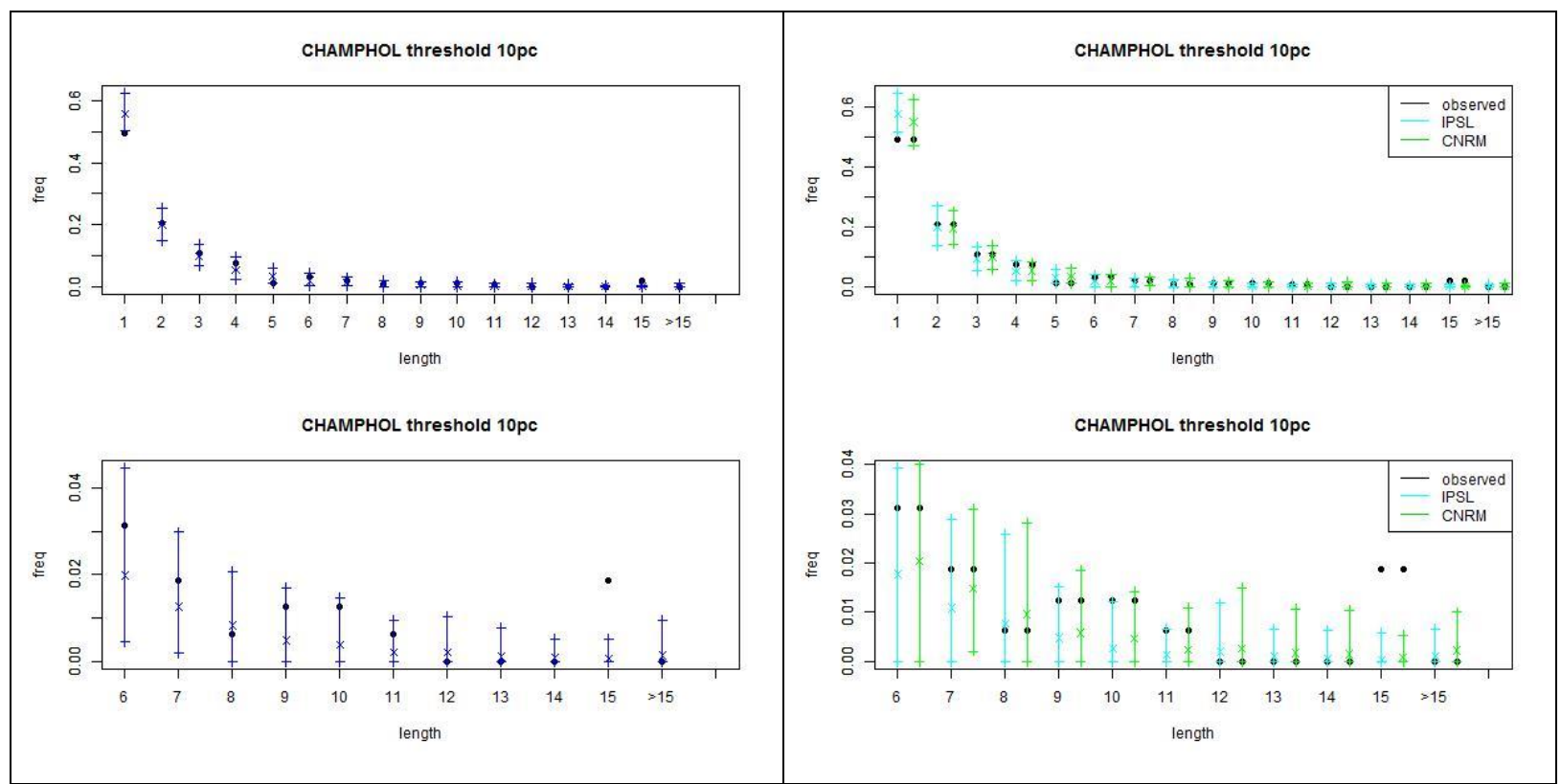

551 Figure 7: cold waves repartition with a $10^{\text {th }}$ percentile threshold for the station of Champhol 552 over period 1980-2005 as given by direct fitting of the stochastic model on the observations

553 (left panel) or by reconstruction using climate model trends and seasonality increments (right 554 panel, IPSL-CM5A-MR in cyan and CNRM-CM5 in green) and stochastic model fitted over 555 period 1954-1979. Black points are for observed proportions while each bar represents the 556 distribution of the 100 simulations ( $\mathrm{x}$ for mean and + for 2.5 and 97.5 percentiles). Top plots 557 represent all cold wave lengths while bottom plots zoom on the longest ones (6 days and 558 more) 


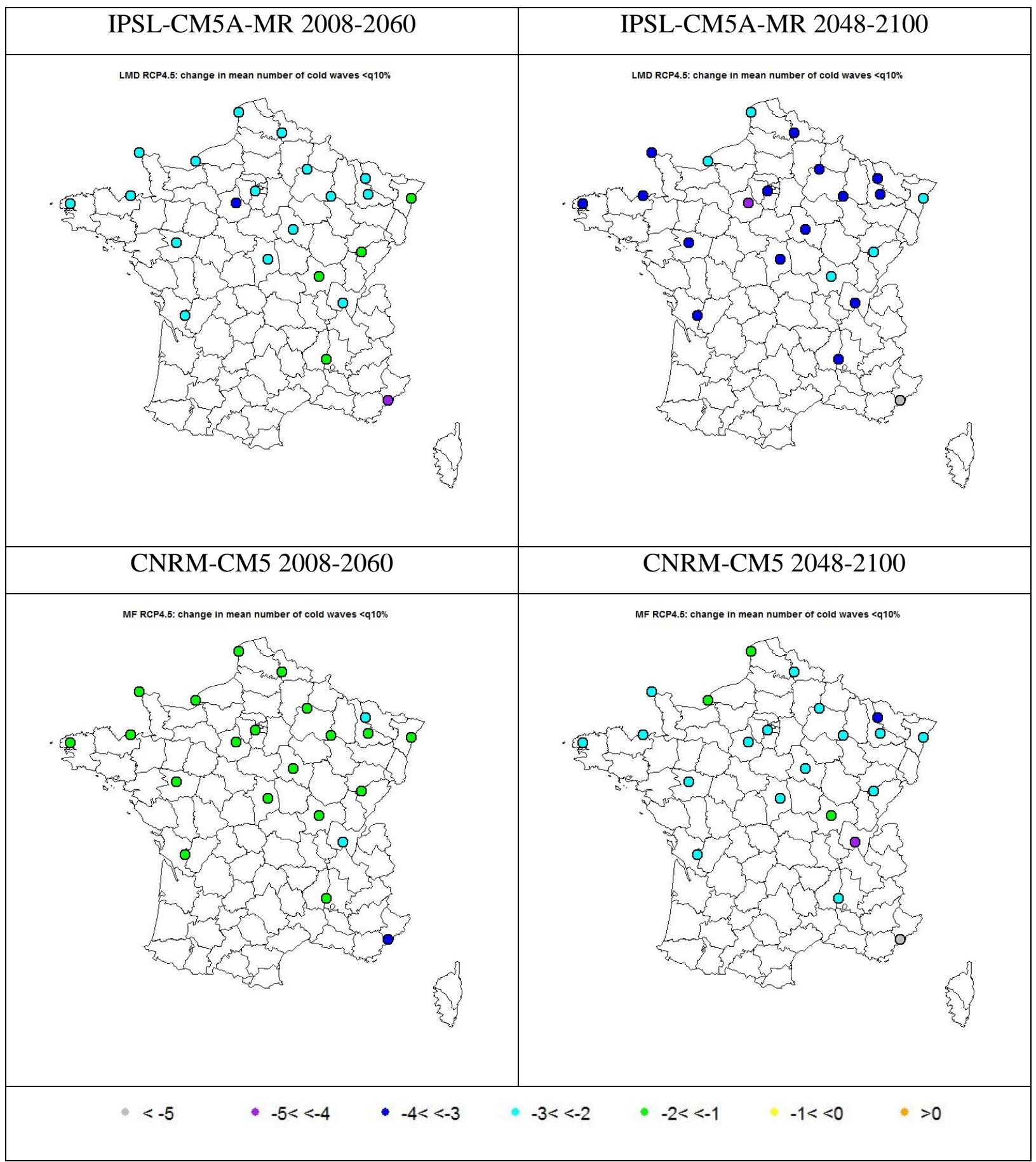

562 Figure 8: change in the mean annual number of cold waves of all duration for the near (ending 563 in 2060, left panel) and far (ending in 2100, right panel) future periods with IPSL-CM5A-MR 564 (top plots) and CNRM-CM5 (bottom plots) models with RCP4.5 with the $10^{\text {th }}$ percentile 565 threshold 


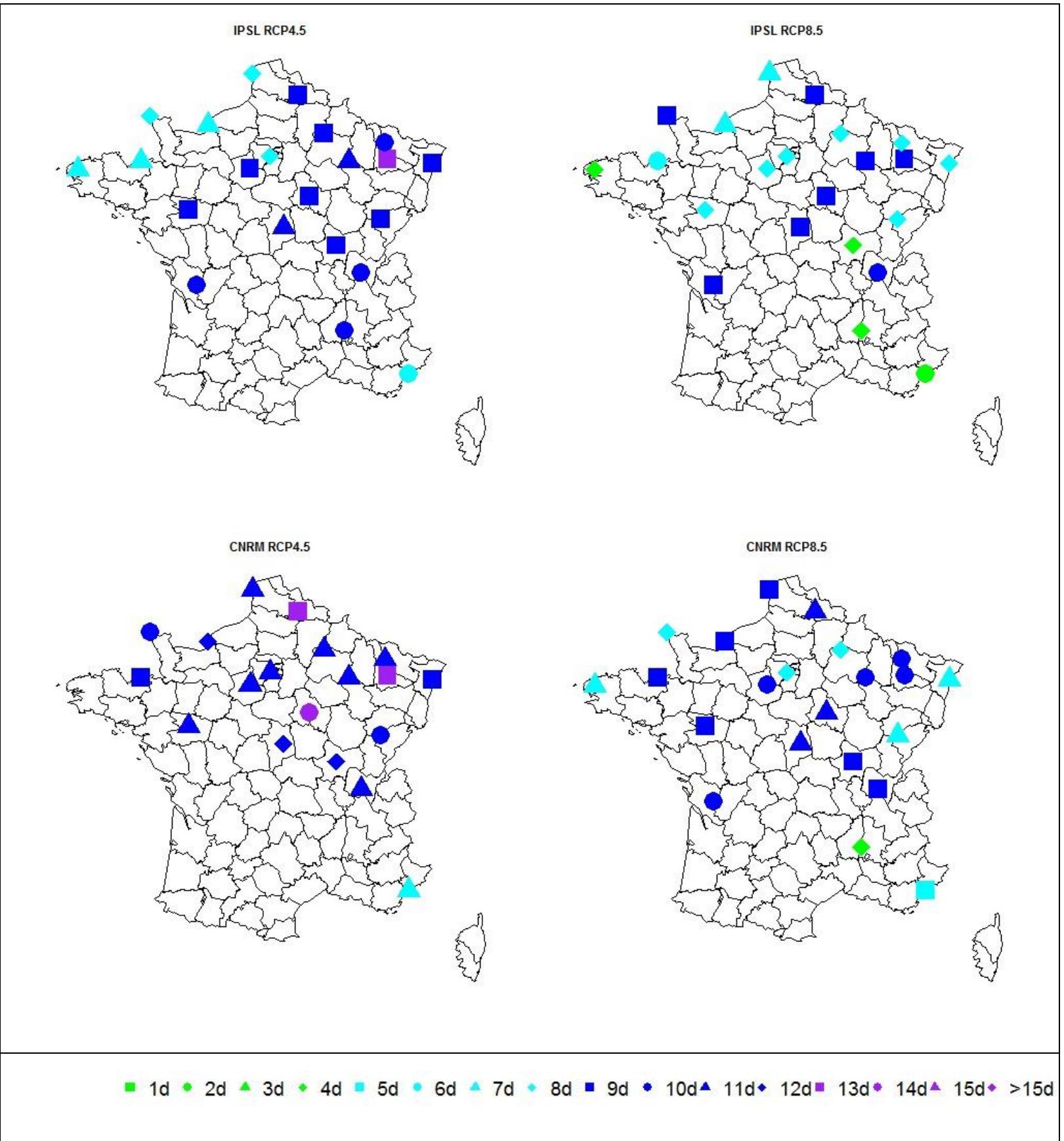

Figure 9: length from which the proportion significantly changes from the observed proportion for future period ending in 2100 according to IPSL-CM5A-MR (top) and CNRM-

570 CM5 (bottom) models with RCP4.5 (left panels) and RCP8.5 (right panels) with the $5^{\text {th }}$ 571 percentile threshold 


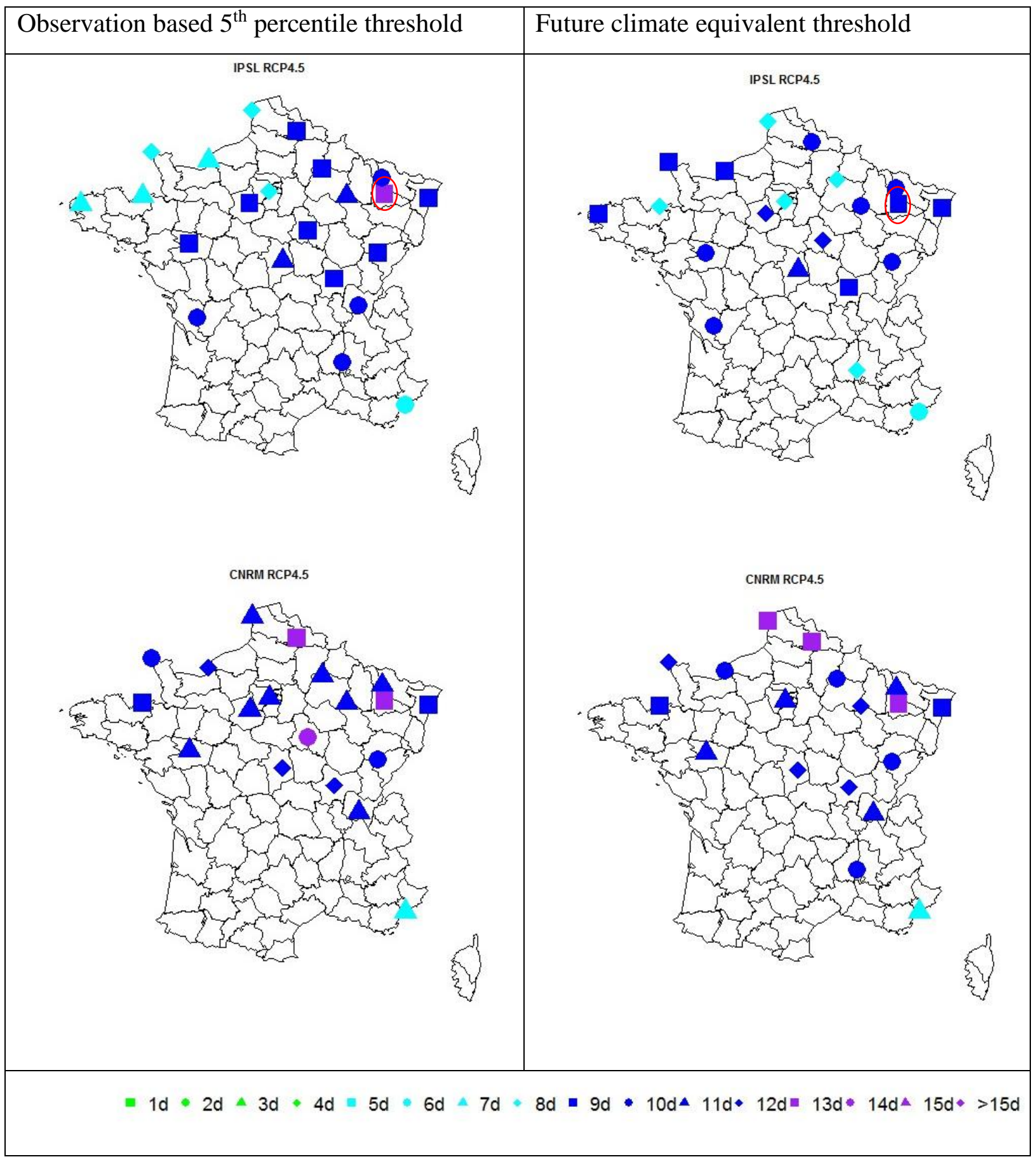

574 Figure 10: length from which changes in proportions of cold waves are significant from the

575 observation based stochastic simulations with the observation based $5^{\text {th }}$ percentile threshold

576 (left panel) and a threshold corresponding to the rank of this observation based $5^{\text {th }}$ percentile

577 threshold in the far future (ending in 2100) wintertime temperature distribution (right panel).

578 Red circling isolates the station of Tomblaine which is further discussed 


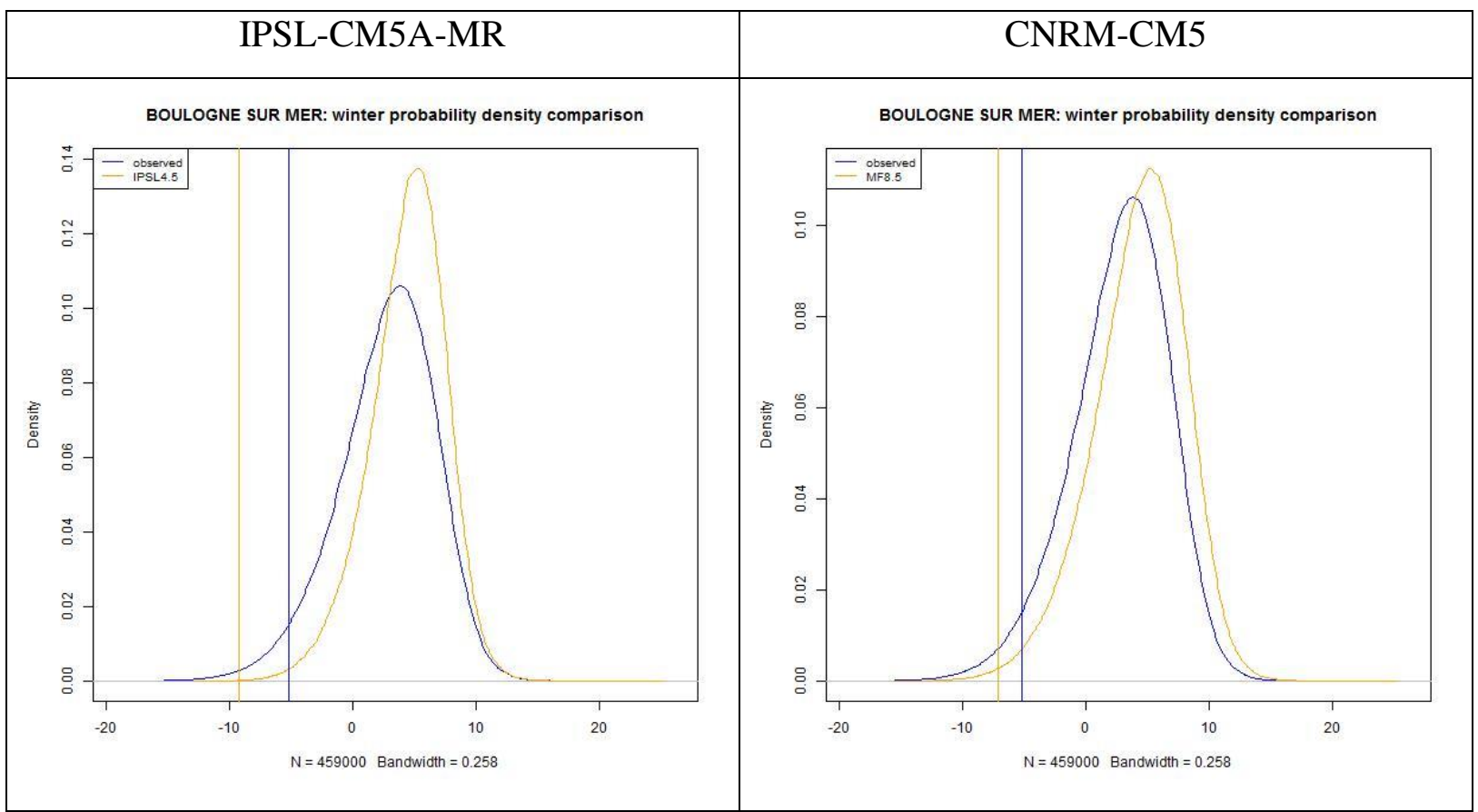

582 Figure 11: probability density function of the wintertime daily minimum temperature 583 according to the observations (blue curve) and climate model far future period with RCP4.5 584 (orange curve) with IPSL-CM5A-MR (left panel) and CNRM-CM5 (right panel). The blue 585 line is for the observation based $5^{\text {th }}$ percentile threshold and the orange one for its equivalent 586 percentile in the future distribution 